Original Research Paper

\title{
Inhibition Effect of Walnut Leaf Polysaccharide on HepG2 Cells in vitro
}

\author{
Shuqing Yang, Haifang Xiao, Shuyan Yu, Zhike Xie, Shaoxuan Yu and Yuanda Song \\ Colin Ratledge Center for Microbial Lipids, \\ School of Agricultural Engineering and Food Science, Shandong University of Technology, Zibo, China
}

\begin{abstract}
Article history
Received: 06-08-2019

Revised: 20-09-2019

Accepted: 26-10-2019

Corresponding Author:

Haifang Xiao and Yuanda Song

Colin Ratledge Center for

Microbial Lipids, School of

Agricultural Engineering and

Food Science, Shandong

University of Technology,

Zibo, China

Email: xiaohaifang@sdut.edu.cn ysong@sdut.edu.cn
\end{abstract}

\begin{abstract}
In this study, the effect of Walnut Leaf Polysaccharides (WLP) on human liver tumor HepG2 cells was investigated. The results showed that WLP had dose-dependent and time-dependent inhibitory effects on HepG2 cell viability. Typical apoptosis characteristics were observed in WLP-treated HepG2 cells through 5,5',6,6'-tetrachloro-1,1',3,3'-tetraethylbenzimidazolyl-carbocyanine iodide (DAPI) staining and Acridine Orange (AO)/Ethidium Bromide (EB) dual staining. Meanwhile, significant decrease in Mitochondrial Membrane Potential (MMP) and increase in intracellular Reactive Oxygen Species (ROS) levels of WLP-induced HepG2 cells were detected by 5,5',6,6'-Tetrachloro-1,1',3,3'tetraethylbenzimidazolcarbocyanine iodide (JC-1) and 2',7'Dichlorodihydrofluorescein Diacetate (DCFH-DA) fluorescent probes, respectively. Moreover, cell viability, MMP and ROS level of HepG2 cells were observed after intervention with antioxidant NAC. Thus, we speculated that WLP may induce apoptosis of HepG2 cells by decreasing MMP and increasing intracellular ROS levels. The results suggest that WLP could be developed as a promising natural anticancer active substance in the pharmaceutical and functional food industries.
\end{abstract}

Keywords: Polysaccharides, Walnut Leaves, HepG2 Cells, Apoptosis, ROS

\section{Introduction}

Polysaccharide is a type of natural biological macromolecule connected by more than 10 monosaccharides through glucoside keys and is one of the basic substances for keeping normal life activities (Kurd and Samavati, 2015; Yu et al., 2018). Polysaccharide is mostly found in animals, plants and microorganisms. Among them, plant polysaccharides are the most widely studied (Shi et al., 2017; Wu et al., 2016; Xie et al., 2016). Researches proved that plant polysaccharides possessed multiple biological functions including anti-diabetes, immune regulation, anticoagulation, antibacterial, antiviral, antioxidant and anticancer activities (Cao et al., 2016; Cheng et al., 2014; He et al., 2015; Jeddou et al., 2016; Li et al., 2019b; Tang et al., 2017; Zhou et al., 2015). In recent years, great attention has been paid to natural polysaccharides due to their unique physico-chemical properties and strong biological actions (Cheng et al., 2014). The international scientific community even put forward the $21 \mathrm{st}$ century is the century of polysaccharides. A large number of evidences make clear that development of newfangled drugs using plant polysaccharides can effectively inhibit cancers (Hu et al., 2016; Li et al., 2017).

Walnut (Juglans regia L.) is the second largest number of tree nuts cultivated in the world. Because of its nutritional and medicinal values, walnut is considered as a kind of natural functional food with high economic value (Li et al., 2019a). The advantageous effectiveness of edible walnuts on the precaution, regulation and remedy of diet-related diseases have been documented and fully demonstrated (Tapia et al., 2013). However, the development and utilization of walnut leaves with strong functional activities are few, resulting in great waste. Walnut leaves can be used as an astringent and preservative in traditional medicine and to make tea. At the same time, walnut leaves possess anti-diarrhea, antiinflammation and anti-ulcer activities (Almeida et al., 2008). Previous studies have assessed the potential of walnut leaf extracts for antimicrobial, antidiabetic and 
antihypertensive effects due to the presence of polyphenols (Forino et al., 2016; Pereira et al., 2007). Judging from the current literatures, the effect of WLP on HepG2 cells remain poorly understood.

Base on the above, the aim of this study was to investigate the inhibited activity of WLP on HepG2 cells. Meanwhile, the mechanism underlying this effect was also explored preliminary.

\section{Materials and Methods}

\section{Materials}

Fresh leaves of walnut were gathered from Zibo city, North of Shangdong, in July 2018. RPMI-1640 and DMEM medium were purchased from Gibco (NY, USA). Thiazolyl blue tetrazolium bromide (MTT) was purchased from Saiguo Biotechnology Co., Ltd (Guangzhou, China). AO/EB staining kit, ROS assay kit, DAPI and JC-1 were purchased from Beyotime Biotechnology Co. Ltd (Shanghai, China). All other reagents were of analytical grade. Ultrapure water was prepared for the experiment.

DZK thermostatic electric oscillating water bath (Shanghai Yiheng Scientific Instrument Co., Ltd.); Forma Steri-Cycle i250 carbon dioxide cell incubator (American Thermo Fisher Scientific Co., Ltd.); EclipseTS100 fluorescence microscope (Japan Nikon Instrument Co. Ltd.); Varioskan Flash multifunctional fluorescent enzyme marker (American Thermo Fisher Scientific Co., Ltd.).

\section{Methods}

\section{Cellulase-Assisted Extraction of the Crude WLP}

Walnut leaf powder was extracted for $2 \mathrm{~h}$ with distilled water assisted by cellulase. The extract extracting solution was deproteinized by Sevage method and then concentrated to an appropriate volume. Thereafter, anhydrous ethanol was added and the solution was kept at $4^{\circ} \mathrm{C}$ for $12 \mathrm{~h}$. The sediments gained by centrifugation at $4000 \mathrm{rpm}$ for $10 \mathrm{~min}$ were lyophilized to obtain the crude WLP (Zhu et al., 2014; Yang et al., 2017; Yin et al., 2018).

\section{Cell Line and Culture}

Human liver cancer cells (HepG2) and human normal liver cells (HL-7702) were obtained from Cell Bank of Institute of Biochemistry and Cell Biology, Chinese Academy of Sciences (Shanghai, China). HepG2 cells were maintained in RPMI-1640 medium added with $10 \%(\mathrm{v} / \mathrm{v}) \mathrm{FBS}$ and $1 \% \mathrm{PS}$ in an incubator with a humidified $5 \% \mathrm{CO}_{2}$ at $37^{\circ} \mathrm{C}$. HL-7702 cells were maintained in DMEM medium added with $10 \%$ (v/v) FBS and $1 \%$ PS in an incubator with a humidified $5 \% \mathrm{CO}_{2}$ at $37^{\circ} \mathrm{C}$.

\section{Cell Viability Assay}

The inhibition ability of WLP on the growth of HepG2 cells was evaluated in vitro using MTT assay (Ren et al., 2015). In this assay, HepG2 cells were seeded in 96 -well plates at a density of $1 \times 10^{4}$ per well for $24 \mathrm{~h}$. Afterwards, the medium was aspirated and new serum-free medium containing serial concentrations $(0$, $1,3,5,7$ and $9 \mathrm{mg} / \mathrm{mL}$ ) of WLP in a volume of $100 \mu \mathrm{L}$ was added. After dealing with different times (12, 24, $36,48 \mathrm{~h}), 20 \mu \mathrm{L}$ of MTT was added to each well and the plate was further incubated for $4 \mathrm{~h}$. Then, MTTcontaining media was discarded and $200 \mu \mathrm{L}$ of DMSO was added into each well for the dissolution of the formation of purple colour formazone crystals. The absorbance was read at $570 \mathrm{~nm}$. Meanwhile, MTT method was used to determine the effect of WLP on cell viability HL-7702 cells after $24 \mathrm{~h}$ treatment of WLP. The cell viability was calculated by the following formula:

$$
\begin{aligned}
& \text { The cell viability }(\%) \\
& =\frac{\text { Absorbance of experimental group }}{\text { Absorbance of bank control group }} \times 100
\end{aligned}
$$

\section{DAPI and AO/EB Staining Analysis}

The cellular morphology changes of cells were visualized by DAPI staining and AO/EB dual staining methods (Palanisamy et al., 2018). HepG2 cells in logarithmic growth-phase were seeded in 6-well plates $\left(3 \times 10^{4}\right.$ /well $)$. After incubated for $24 \mathrm{~h}$, cells were exposed to WLP $(1,5,9 \mathrm{mg} / \mathrm{mL})$, with the RPMI-1640 medium as the control. After $12 \mathrm{~h}$, cells were washed twice with PBS and fixed using a mixture of methanol and glacial acetic acid $(3: 1, \mathrm{v} / \mathrm{v})$ at $4^{\circ} \mathrm{C}$ for $20 \mathrm{~min}$. Then, the cells were washed with PBS solution and stained by DAPI $(5 \mu \mathrm{g} / \mathrm{mL})$ and $\mathrm{AO} / \mathrm{EB}(50 \mu \mathrm{g} / \mathrm{mL})$ for $30 \mathrm{~min}$ in the dark, respectively. The apoptosis changes were observed under a fluorescence microscope (Nikon, EclipseTS100, Japan) at 40× magnification.

\section{JC-1 Assay for MMP}

$\mathrm{JC}-1$ is an ideal fluorescent probe widely used to detect MMP. The MMP was investigated according to the method reported by Yan et al. with slight modifications (Yan et al., 2016). HepG2 cells $\left(1 \times 10^{4} /\right.$ well $)$ were inoculated in 96 -well plates and cultured overnight. After treated with WLP (1, 5, 9 $\mathrm{mg} / \mathrm{mL}$ ) for $24 \mathrm{~h}$, HepG2 cells were washed with PBS twice and then stained by $\mathrm{JC}-1(10 \mu \mathrm{g} / \mathrm{mL})$ at $37^{\circ} \mathrm{C}$ for 30 min. JC-1 staining of cells was observed by fluorescence microscopy and photographed. The MMP was quantitatively detected with a microplate fluorometer and the results were expressed by green/red fluorescence intensity. 


\section{Measurement of Intracellular ROS}

The intracellular ROS levels of HepG2 cells were detected by fluorescence using DCFH-DA, as described by Ren et al. with a little change (Ren et al., 2015). Briefly, the cell suspensions of HepG2 $\left(1 \times 10^{4} /\right.$ well $)$ were pipetted into a 96-well plate and hatched for $24 \mathrm{~h}$ to allow attachment. Afterwards, cells were incubated in different concentrations $(1,5,9 \mathrm{mg} / \mathrm{mL})$ of WLP or RPMI-1640 medium for another $24 \mathrm{~h}$ and subsequently rinsed twice with PBS. Thereafter, the cells were incubated with DCFH-DA (10 $\mu \mathrm{mol} / \mathrm{L}$ ) at $37^{\circ} \mathrm{C}$ for $20 \mathrm{~min}$. The fluorescence intensity produced by DCFH-DA in HepG2 cells was estimated with fluorescence microplate quantitatively and fluorescence microscope qualitatively. The ROS levels were indicated by percentages relative to the fluorescence strength of the untreated control cells (100\%).

\section{Statistical Analysis}

The experimental design and statistically analysis of the results of RSM were executed by Design-Expert Version software (version 8.0.6.1, State-Ease, Inc., Minneapolis, MN, USA). All data were indicated as the means \pm Standard Deviation (SD) and evaluated using Analysis Of Variance (ANOVA). For all comparisons, a significant difference was judged to be statistically significant if $p<0.05$.

\section{Results and Discussion}

\section{WLP Effectively Inhibit Viability of HepG2 Cells}

In this study, the anti-proliferation effects of varying concentrations of WLP $(1,3,5,7$ and $9 \mathrm{mg} / \mathrm{mL})$ on HepG2 cells were determined by MTT method, respectively. As shown in Fig. 1, WLP presented a doseand time- dependent proliferation-inhibitory effects against HepG2 cells. The highest concentration of WLP $(9 \mathrm{mg} / \mathrm{mL})$ behaved the most remarkable effectiveness regarding cell viabilities $(66.38 \%, 25.43 \%, 25.83 \%$ and $9.92 \%$ at $24 \mathrm{~h}, 36,48 \mathrm{~h}$ and $72 \mathrm{~h}$, respectively). The IC50 values of WLP in inhibiting viabilities of HepG2 cells for the four different processing times were 8.85, $6.52,5.56,4.79 \mathrm{mg} / \mathrm{mL}$, respectively. In addition, it can be seen from Fig. 2 that WLP has no inhibitory significant effect on normal liver cells HL-7702. These findings were similar to the previous reports on other polysaccharides, such as polysaccharides collected from Sargassum fusiforme and Ligusticum chuanxiong Hort (Chen et al., 2012; Yuan et al., 2008). Moreover, sulfated polysaccharides from Sargassum plagiophyllum had the potential to interact with genes involved in cell cycle period and also to inveigle DNA injury and apoptosis in HepG2 cells (Suresh et al., 2013).

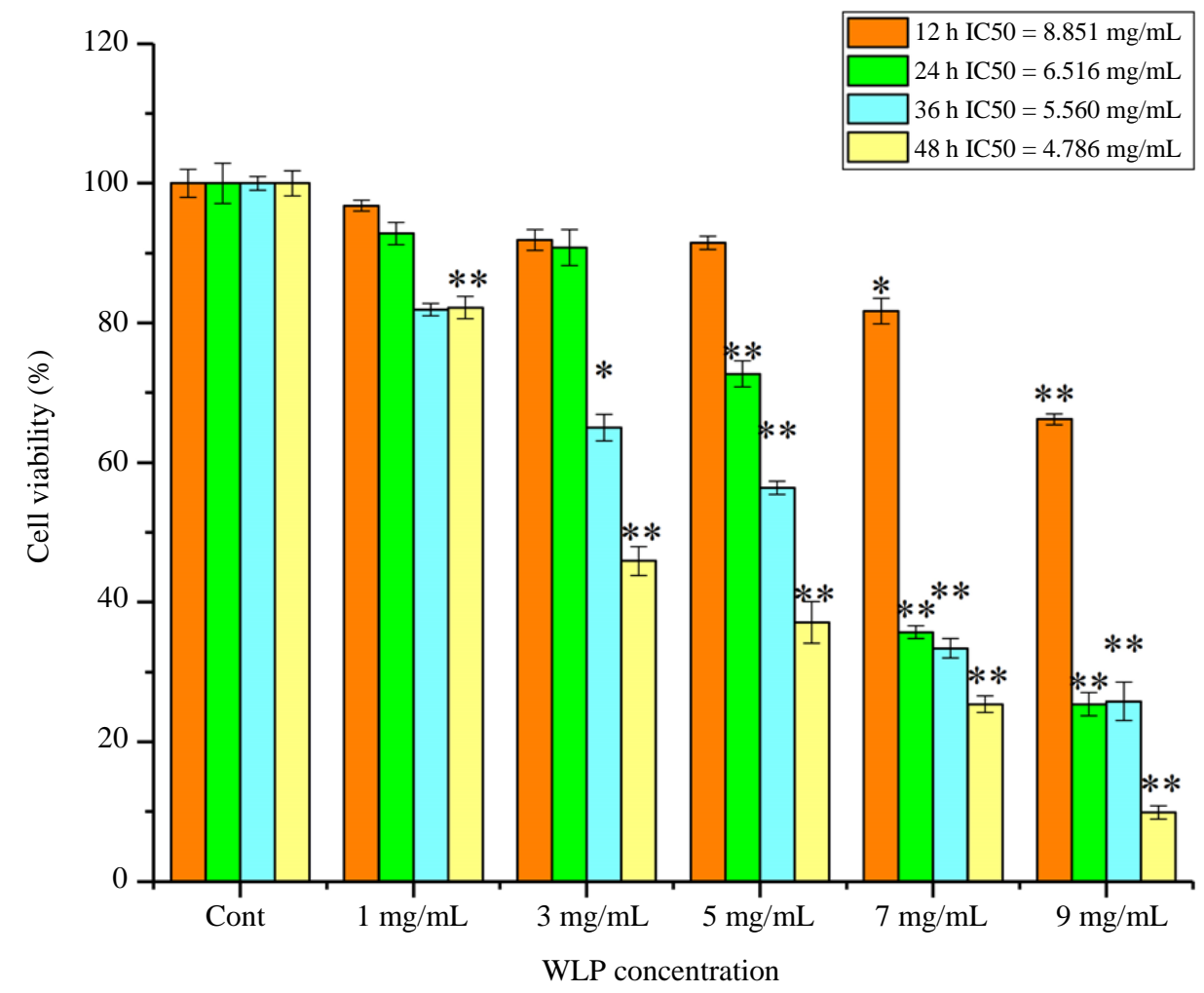

Fig. 1: In vitro anticancer activity assay of WLP against HepG2. Cell viability was determined by MTT colorimetric assay after treatment with different concentrations $(1,3,5,7,9 \mathrm{mg} / \mathrm{mL})$ of WLP for different times $(12,24,36,48 \mathrm{~h})$. Each value represents the mean $\pm \mathrm{SD}$ of three determinations. ${ }^{*} \mathrm{p}<0.05$ and $* * \mathrm{p}<0.01$ indicate statistical significance 


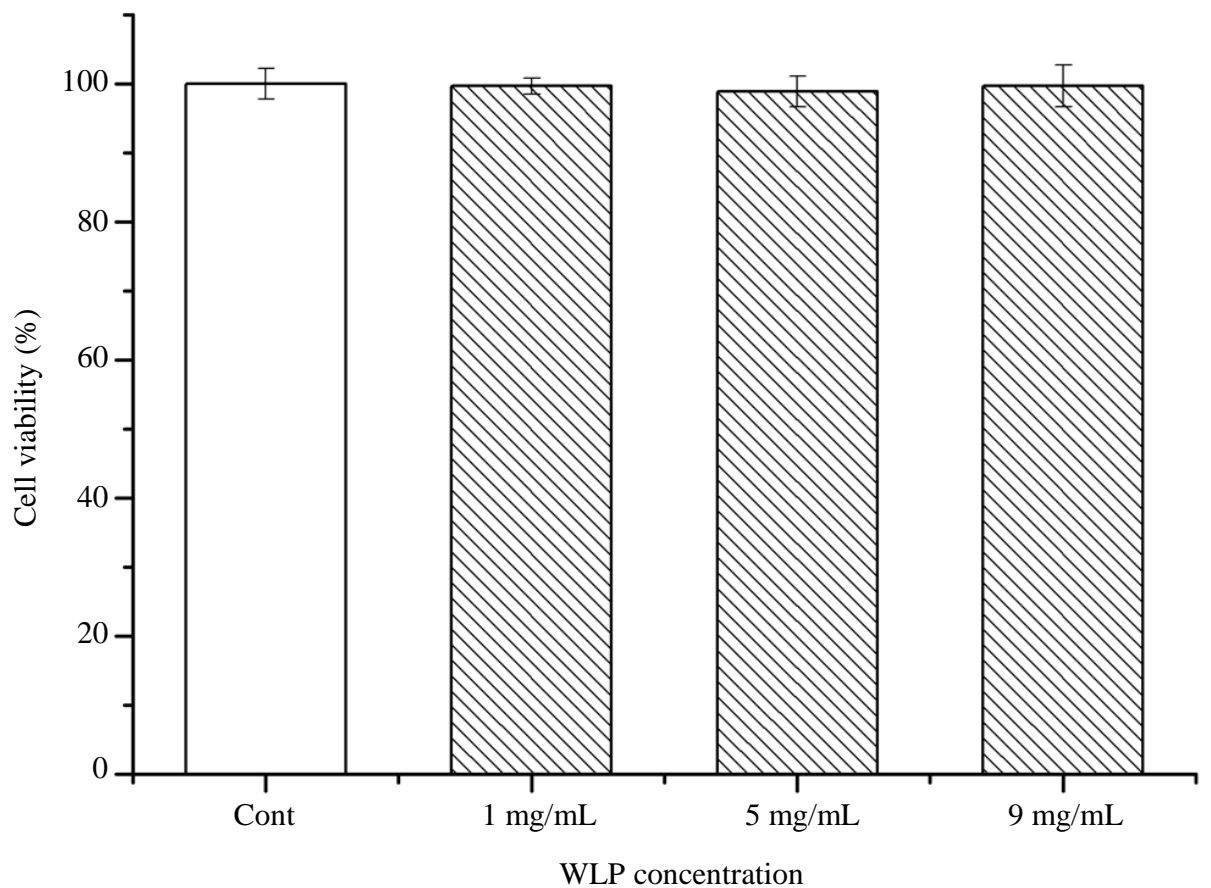

Fig. 2: The effect of WLP on the viability of HL-7702 cells. Cell viability was determined by MTT colorimetric assay after treatment with different concentrations $(1,5,9 \mathrm{mg} / \mathrm{mL})$ of WLP for $24 \mathrm{~h}$. Each value represents the mean $\pm \mathrm{SD}$ of three determinations

\section{WLP Induces Apoptosis of HepG2 Cells}

Apoptosis is a basic biological phenomenon of cells, which is not only a special type of cell death, but also has important biological significance and complex molecular biological mechanism. Current research indicates that inducing apoptosis in cancer cells is one of the effective anti-cancer mechanisms and a significant factor in the success of medicinal discovery (Suresh et al., 2013). Apoptosis is mainly characterized by changes in morphology and biochemistry. Thus, the occurrence of apoptosis can be judged by evaluating the appearance features of cells and is diffusely utilized for various medical studies (Doonan and Cotter, 2008). The morphological variations of HepG2 cells treated with WLP observed by fluorescence microscopy were shown in Fig. 3. From the pictures in Fig. 3, we found out that the cells in the control group were clearly contoured with a representative irregular fusiform form, whereas the cytomorphology was changed after WLP treatment. When cells were treated with low concentration of WLP $(1 \mathrm{mg} / \mathrm{mL})$, the basic morphology of HepG2 cancer cells altered unobviously. However, HepG2 cells cultured with medium $(5 \mathrm{mg} / \mathrm{mL})$ and high $(9 \mathrm{mg} / \mathrm{mL})$ doses of WLP showed obvious characteristics of apoptotic, including cell contraction deformation, blurred contour, chromatin condensation and nuclear condensation (Palanisamy et al., 2018). In this study, the apoptotic morphology of HepG2 cells induced by WLP were ulteriorly verified by DAPI-staining.

DAPI is a blue fluorescent dye that strongly binds to DNA through cell membranes and is frequently used to identify apoptosis (Palanisamy et al., 2018). As shown in Fig. 4, normal HepG2 cells presented uniform staining and complete nuclear morphology, while the cell nucleus of HepG2 cells treated with WLP was densely stained as WLP concentration increased to $9 \mathrm{mg} / \mathrm{mL}$. The analogous outcome was viewed in the previous research of Sargassum cristaefolium polysaccharides-treated human colon cancer cells (Wang et al., 2015).

$\mathrm{AO}$ is a kind of nucleic acid-selective fluorescent cationic dye that can penetrate normal cell membranes and glow uniform green or yellow-green fluorescence after combined with nuclear DNA. EB can only dye cells that have lost membrane integrality in red. Therefore, $\mathrm{AO}$ is commonly double-stained with EB to distinguish normal cells from apoptotic cells. As can be seen from Fig. 5, compared to the control cells, the green light tended to become weaker and the red gradually enhanced in HepG2 cells treated with WLP, indicating an increase in cell membrane permeability. Otherwise, under the fluorescence microscope, several different cell forms were observed: Living cells, showing structure-like features of various shades of green fluorescence; early apoptotic cells, the nuclear chromatin was green in a condensed or rounded like; in late apoptotic cells, orange-red pyknotic chromatin could be seen. 

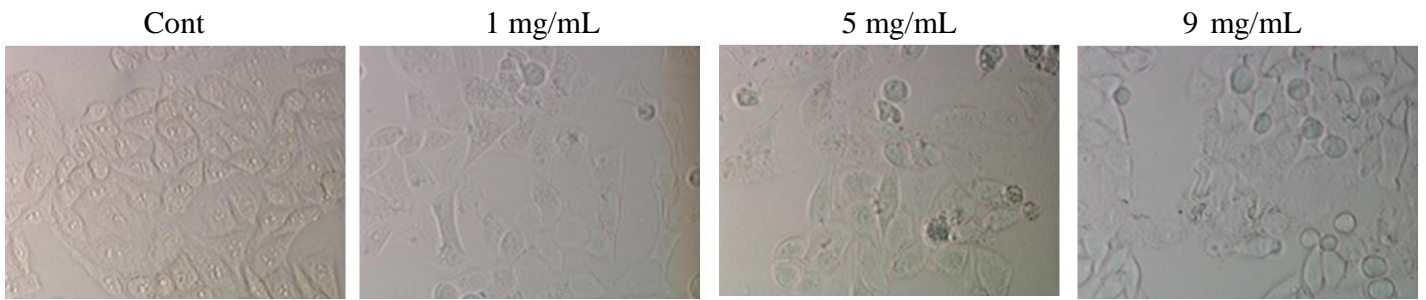

Fig. 3: Morphological observation of control and WLP-treated HepG2 cells for $12 \mathrm{~h}$. Morphological observation by inverted microscope
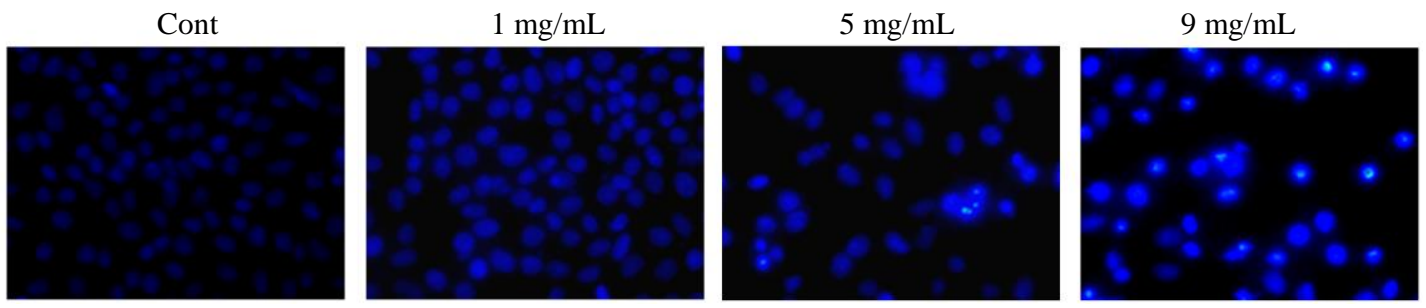

Fig. 4: Morphological observation of control and WLP-treated HepG2 cells for $12 \mathrm{~h}$. DAPI staining analysis of the induction of apoptosis in HepG2 cells, visualized under fluorescence microscopy
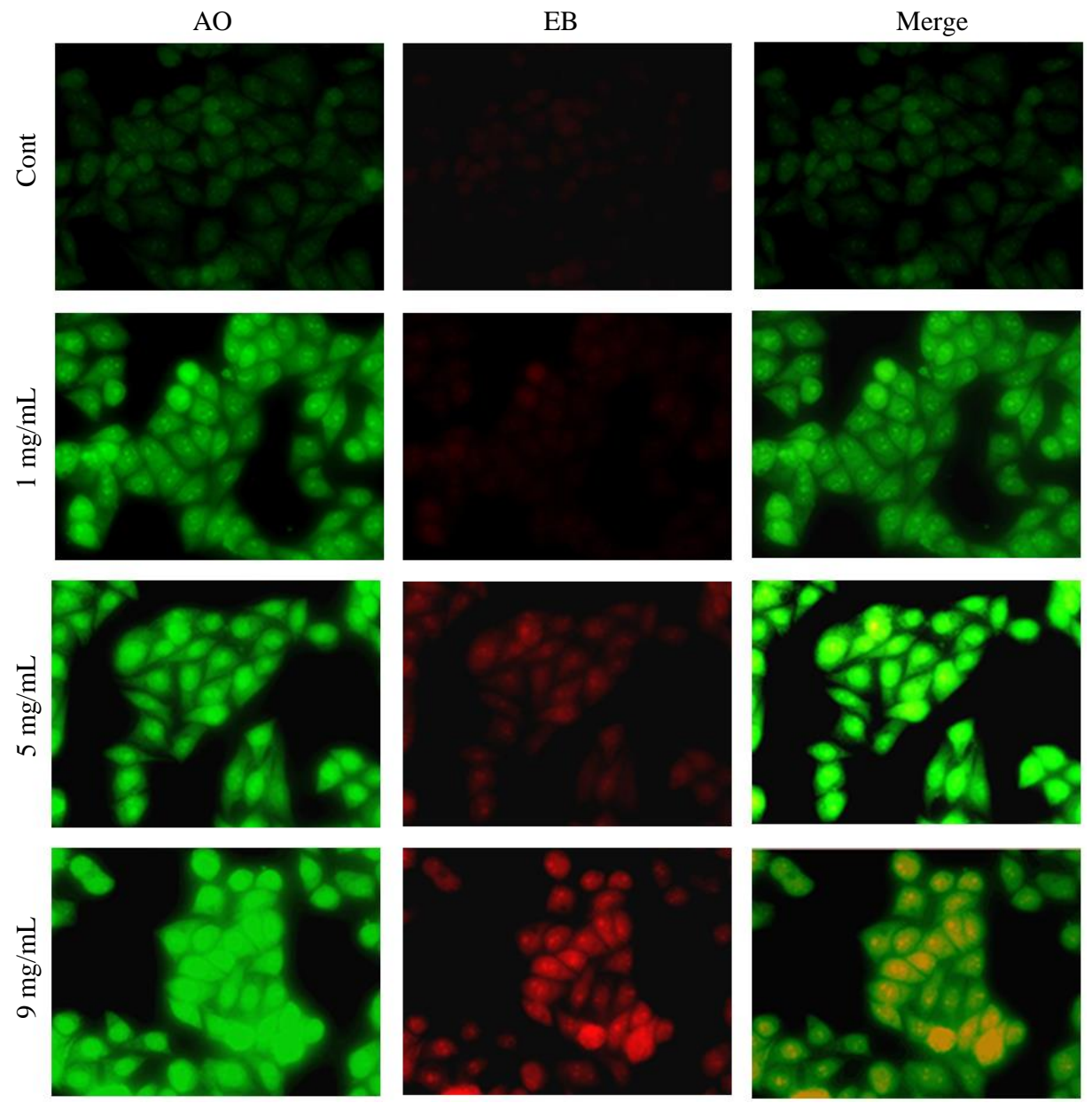

Fig. 5: Morphological observation of control and WLP-treated HepG2 cells for $12 \mathrm{~h}$. AO/EB staining analysis of the induction of apoptosis in HepG2 cells, visualized under fluorescence microscopy 

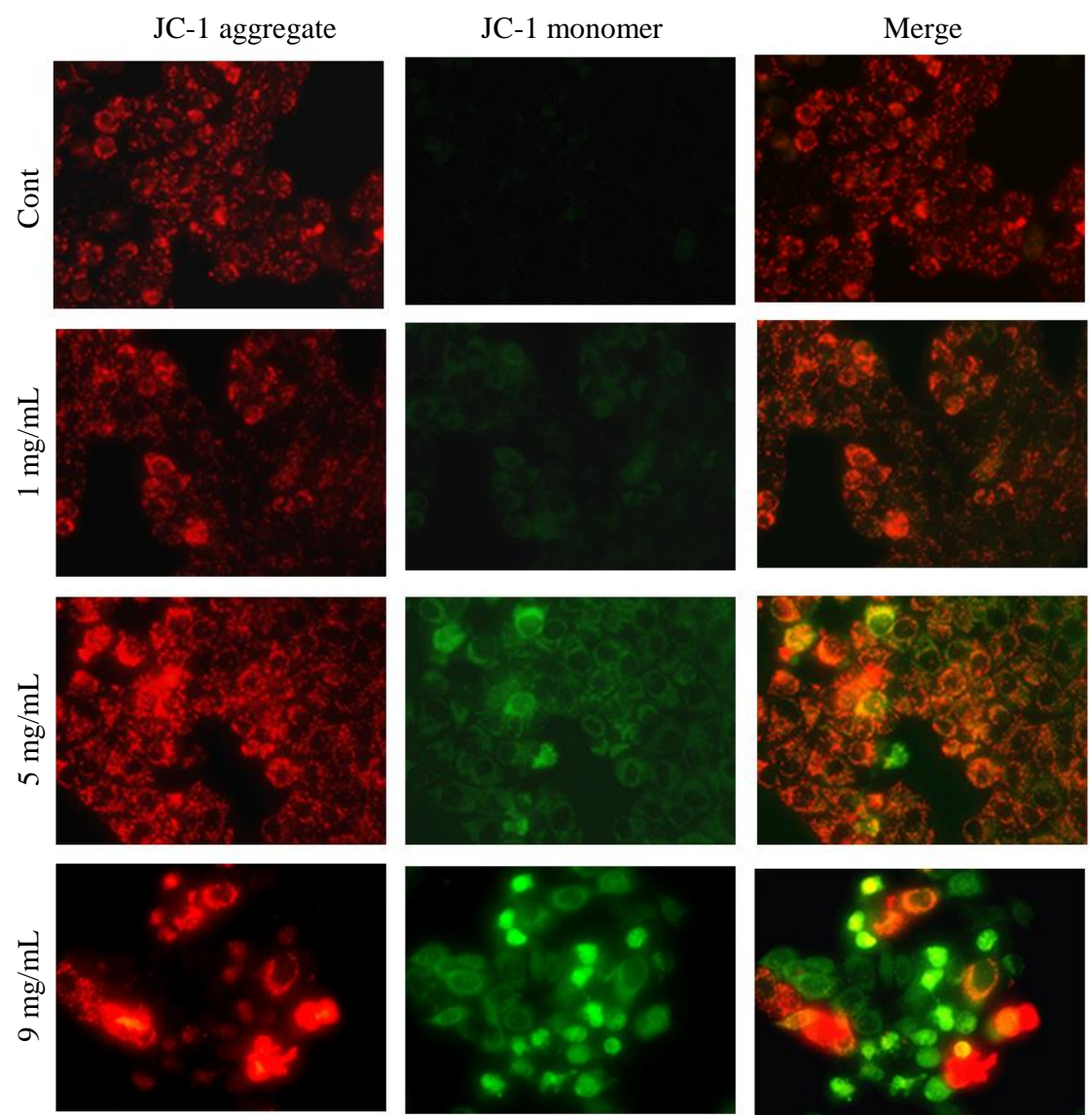

(A)

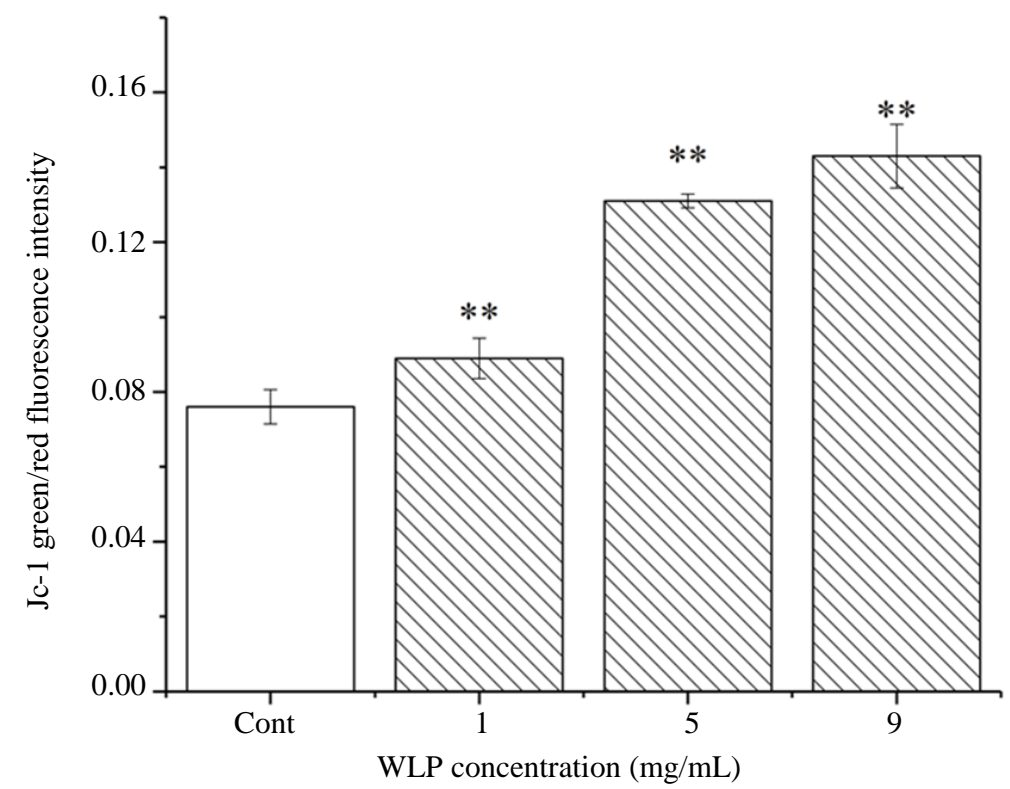

(B)

Fig. 6: JC-1 assay for MMP. HepG2 cells were stained with JC-1 after treated with WLP for $24 \mathrm{~h}$, with the normal nutrient solution treated cells as the control group. (A) Qualitative analysis by fluorescence microscope. (B) Quantitative analysis with fluorescence enzyme marker. Each value represents the mean $\pm \mathrm{SD}$ of three determinations. ${ }^{*} \mathrm{p}<0.05$ and $* * \mathrm{p}<0.01$ indicate statistical significance 


\section{WLP Reduce the MMP of HepG2 Cells}

The decreased MMP is a landmark event in the early stage of cell apoptosis. $\mathrm{JC}-1$ is an ideal fluorescent probe which can quickly and sensitively detect the potential changes of mitochondrial membrane in cells. Under the high MMP, JC-1 aggregates in the form of a polymer in the mitochondrial matrix to generate red fluorescence. Once the MMP decreases, JC-1 mainly exists in the cytoplasm as a monomer and emits green fluorescence. In this way, changes in MMP can be easily detected by the transformation of JC-1 from red to green. Therefore, the percent of cells with

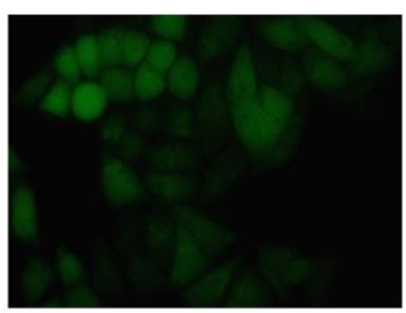

Cont

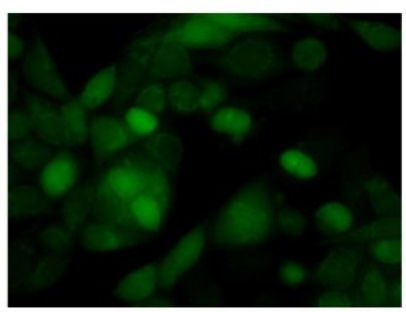

$5 \mathrm{mg} / \mathrm{mL}$

(A)

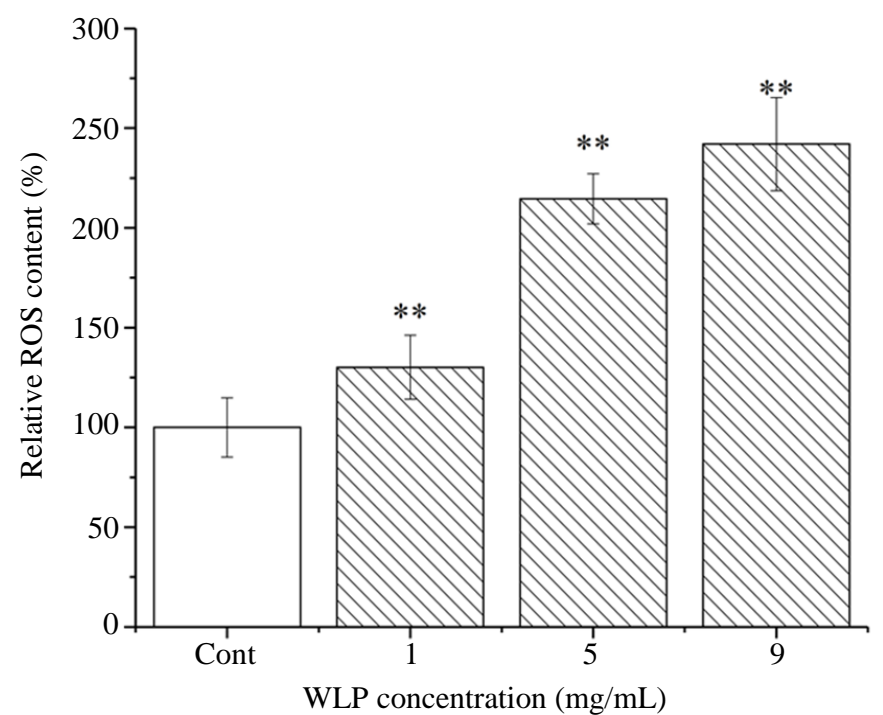

(B)

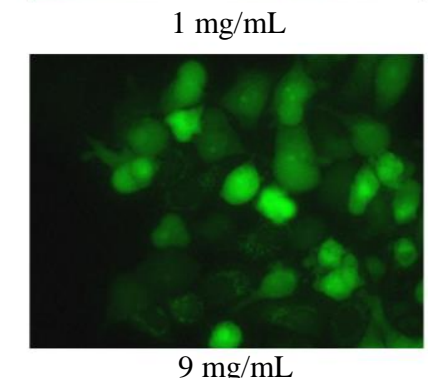

A) depolarized mitochondria is commonly quantified by the relative proportion of red-green fluorescence.

The MMPs of HepG2 cells treated with WLP were analyzed in this study. After treatment, the green fluorescence of HepG2 cells was significantly enhanced, indicating that WLP caused changes in mitochondrial permeability and thus reduced MMP in HepG2 cells (Fig. 6A). The quantitative analysis of MMP of HepG2 cells was presented in Fig. 6B. We found a concentration-dependent increase in green/red fluorescence intensity of HepG2 cells. Similarly, other active substances, such as polysaccharides from Chuanxiong rhizome, had strong effects on the inhibition of HepG2 cells (Hu et al., 2016).

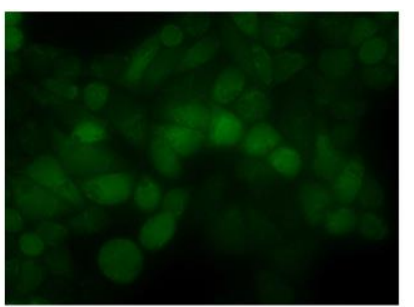

$1 \mathrm{mg} / \mathrm{mL}$

$9 \mathrm{mg} / \mathrm{mL}$ 


\section{WLP Increase ROS Level of HepG2 Cells}

The elevated levels of ROS have toxic effects on HepG2 cells. Therewith, we hypothesized that the marked antiproliferative effect of WLP on HepG2 cells may be due in part to the production of endocellular ROS, which ultimately leads to an imbalance in the redox status of HepG2 cells (López-García et al., 2017). To validate this assumption, the levels of ROS in WLPtreated HepG2 cells were assessed by DCFH-DA method. DCFH-DA could be hydrolyzed into DCFH by intracellular esterase and then the active oxygen in the cells oxidizes the non-fluorescent DCFH to generate fluorescent DCF. As a consequence, the fluorescence of
DCF is the standard for judging the levels of ROS in cells. In Fig. 7A, diverse concentrations of WLP treatment increased the intensity of green fluorescence in a dosage-dependent pattern, manifesting the cumulation of intrastitial ROS, which was consistent with the quantitative result of ROS level by a multi-function microplate reader in Fig. 7B. Compared with untreated control cells, the intracellular ROS levels of HepG2 cells treated with different concentrations of WLP $(1,5$ and 9 $\mathrm{mg} / \mathrm{ml}$ ) for $24 \mathrm{~h}$ were signally increased to $130.18 \%$, $214.62 \%$ and $242.06 \%$, respectively. The polysaccharides obtained from P. Abalonus and Salvia miltiorrhiza Bunge can augment oxydic stress-induced apoptosis in tumor cells (Ren et al., 2015; Wang et al., 2018).

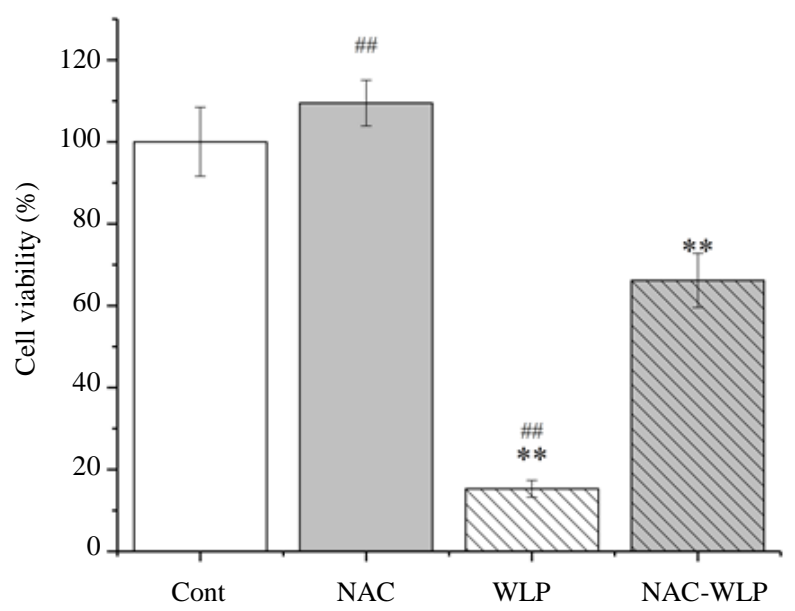

(A)

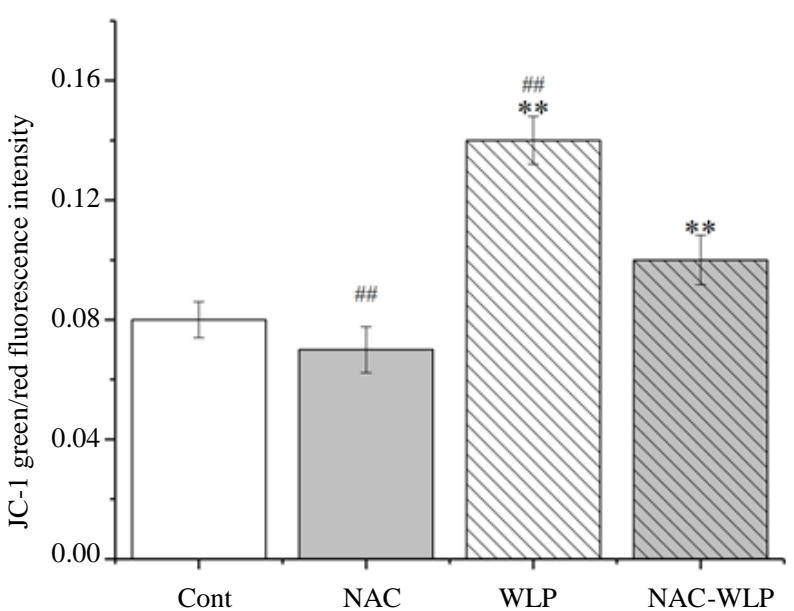

(B)

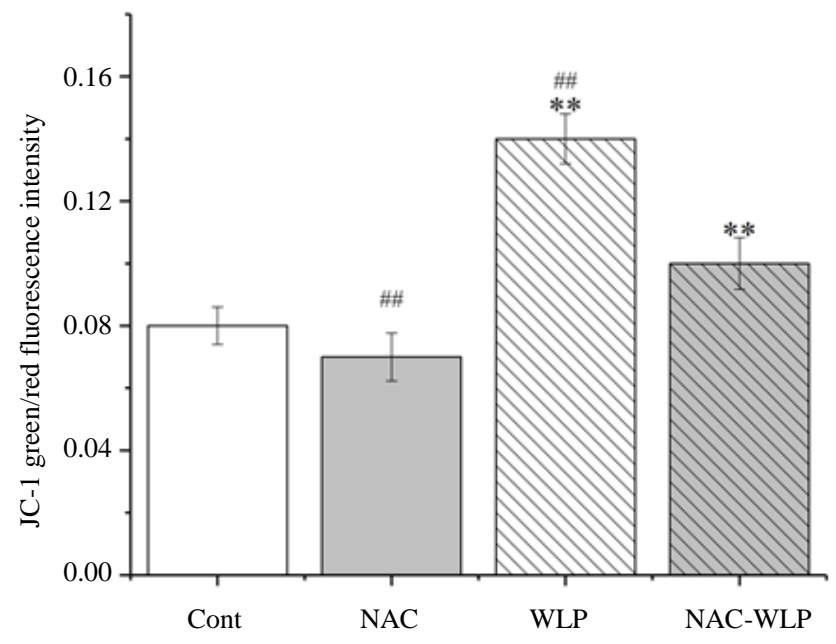

(C)

Fig. 8: WLP was verified to induce apoptosis by increasing intracellular ROS levels. HepG2 cells were treated with WLP and cell viability (A), MMP (B) and ROS levels (C) were measured in the absence or presence of antioxidant NAC pretreatment. Each value represents the mean $\pm \mathrm{SD}$ of three determinations. ${ }^{*}<<0.05$ and $* * p<0.01$ indicate statistical significance 
Antioxidant NAC was employed to further determine whether HepG2 apoptosis was related to oxidative stress. Our results demonstrated that WLP lowered the survival rate of cancer cells (30.8\% of control group), however, NAC pretreatment significantly prevented the decrease in the viability of HepG2 cells induced by WLP (Fig. 8A). In addition, changes in MMP of HepG2 cells showed that NAC led to the prevention of mitochondrial depolarization (Fig. 8B). Further evaluation of ROS level revealed that NAC treatment alleviated the increased ROS level in WLP-treated HepG2 cells (Fig. 8C).

\section{Conclusion}

In this paper, the anticancer activity of WLP on HepG2 cells in vitro was evaluated. Results showed that WLP inhibited the viability of HepG2 cells in dose- and time-dependent manner. DAPI and AO/EB staining tests verified the apoptosis of HepG2 cells induced by WLP. Meanwhile, the decrease of MMP was detected by using JC-1 fluorescent probe. We also found that WLP induced the increase of ROS level in HepG2 cells. Moreover, antioxidant NAC alleviated the changes of cell viability, MMP and ROS level in WLP-treated HepG2 cells. Thus, we speculated that WLP might induce apoptosis of HepG2 cells by ROS-mediated mitochondrial pathway. Mitochondrial pathway, also known as endogenous pathway in cell apoptosis, is mainly regulated by Bcl-2, which induces the decrease of MMP, increases membrane permeability, promotes the release of cytochrome $\mathrm{c}$ and impairs mitochondrial function. Several studies have found that ROS can lead to mitochondrial dysfunction and induce apoptosis in HepG2 cells (Hu et al., 2013; Jose et al., 2018). We will deeply explore the apoptosis mechanism involved of mitochondrial pathway and ROS in HepG2 cells induced by WLP through multiple approaches in future work. Moreover, previous studies proved that polysaccharides can first interact with cell surface receptors, such as TLR2, TLR4, Dectin-1, SR, CR3, etc. and then trigger activation of intracellular signal pathways to exert their effects (Zhou et al., 2017). Our further researches will focus on investigating whether WLP exerts its effects on HepG2 cells by interacting with cell surface receptors firstly.

\section{Acknowledgement}

This work was supported by SDUT and Zibo City Integration Development Project (2017ZBXC004) and Shandong Provincial Natural Science Foundation, China (No. ZR2014CQ002). Therefore, we are grateful for the funding and support of this research.

\section{Funding Information}

This work was supported by SDUT and Zibo City Integration Development Project (2017ZBXC004) and
Shandong Provincial Natural Science Foundation, China (No. ZR2014CQ002).

\section{Author's Contributions}

Shuqing Yang: Participated in the whole experiment process and also contributed to the interpretation of the results and manuscript preparation.

Haifang Xiao: Contributed to the study design, the interpretation of the results and manuscript preparation.

Shuyan Yu and Zhike Xie: Participated in part of the experimental design.

Shaoxuan Yu: Ameliorated the manuscript.

Yuanda Song: Contributed to the guidance of experimental design and ameliorated the manuscript.

\section{Ethics}

This article is original and contains unpublished material. The corresponding author confirms that all of the other authors have read and approved the manuscript and no ethical issues involved.

\section{References}

Almeida, I.F., E. Fernandes, J.L.F.C. Lima, P.C. Costa and M. Fernanda Bahia, 2008. Walnut (Juglans regia) leaf extracts are strong scavengers of prooxidant reactive species. Food Chem., 106: 1014-1020. DOI: 10.1016/j.foodchem.2007.07.017

Cao, Y.G., Y. Hao, Z.H. Li, S.T. Liu and L.X. Wang, 2016. Antiviral activity of polysaccharide extract from Laminaria japonica against respiratory syncytial virus. Biomed. Pharmacother, 84: 1705-1710.

DOI: 10.1016/j.biopha.2016.10.082

Chen, X., W. Nie, G. Yu, Y. Li and Y. Hu et al., 2012. Antitumor and immunomodulatory activity of polysaccharides from Sargassum fusiforme. Food Chem. Toxicol., 50: 695-700.

DOI: 10.1016/j.fct.2011.11.015

Cheng, B.H., J.Y. Chan, B.C. Chan, H.Q. Lin and X.Q. Han et al., 2014. Structural characterization and immunomodulatory effect of a polysaccharide HCP2 from Houttuynia cordata. Carbohydr. Polym., 103: 244-249. DOI: 10.1016/j.carbpol.2013.12.048

Doonan, F. and T.G. Cotter, 2008. Morphological assessment of apoptosis. Methods, 44: 200-204. DOI: 10.1016/j.ymeth.2007.11.006

Forino, M., P. Stiuso, S. Lama, P. Ciminiello and G.C. Tenore et al., 2016. Bioassay-guided identification of the antihyperglycaemic constituents of walnut (Juglans regia) leaves. J. Funct. Foods, 26: 731-738. DOI: 10.1016/j.jff.2016.08.053

He, R., Y. Zhao, R. Zhao and P. Sun, 2015. Antioxidant and antitumor activities in vitro of polysaccharides from E. sipunculoides. Int. J. Biol. Macromol., 78: 56-61. DOI: 10.1016/j.ijbiomac.2015.03.030 
Hu, J., X. Jia, X. Fang, P. Li and C. He et al., 2016. Ultrasonic extraction, antioxidant and anticancer activities of novel polysaccharides from Chuanxiong rhizome. Int. J. Biol. Macromol., 85: 277-284. DOI: 10.1016/j.ijbiomac.2015.12.046

$\mathrm{Hu}, \mathrm{M}$., Y. Chen, C. Wang, H. Cui and P. Duan et al., 2013. Induction of apoptosis in $\mathrm{HepG}_{2}$ cells by polysaccharide MEP-II from the fermentation broth of Morchella esculenta. Biotechnol. Lett., 35: 1-10. DOI: 10.1007/s10529-012-0917-4

Jeddou, K.B., F. Chaari, S. Maktouf, O. Nouri-Ellouz and C.B. Helbert et al., 2016. Structural, functional and antioxidant properties of water-soluble polysaccharides from potatoes peels. Food Chem., 205: 97-105. DOI: 10.1016/j.foodchem.2016.02.108

Jose, G.M., M. Raghavankutty and G.M. Kurup, 2018. Sulfated polysaccharides from Padina tetrastromatica induce apoptosis in HeLa cells through ROS triggered mitochondrial pathway. Process Biochem., 68: 197-204.

DOI: $10.1016 /$ j.procbio.2018.02.014

Kurd, F. and V. Samavati, 2015. Water soluble polysaccharides from Spirulina platensis: Extraction and in vitro anti-cancer activity. Int. J. Biol. Macromol., 74: 498-506.

DOI: 10.1016/j.ijbiomac.2015.01.005

Li, Y., X. Tian, S. Li, L. Chang and P. Sun et al., 2019a. Total polysaccharides of adlay bran (Coix lachrymajobi L.) improve TNF-alpha induced epithelial barrier dysfunction in Caco-2 cells via inhibition of the inflammatory response. Food Funct., 10: 2906-2913. DOI: 10.1039/c9fo00590k

Li, L., L. Song, X. Sun, S. Yan and W. Huang et al., 2019b. Characterisation of phenolics in fruit septum of Juglans regia Linn. by ultra performance liquid chromatography coupled with Orbitrap mass spectrometer. Food Chem., 286: 669-677. DOI: 10.1016/j.foodchem.2019.02.054

Li, S., A. Gao, S. Dong, Y. Chen and S. Sun et al., 2017. Purification, antitumor and immunomodulatory activity of polysaccharides from soybean residue fermented with Morchella esculenta. Int. J. Biol. Macromol., 96: 26-34.

DOI: 10.1016/j.ijbiomac.2016.12.007

López-García, G., A. Cilla, R. Barberá and A. Alegría, 2017. Antiproliferative effect of plant sterols at colonic concentrations on Caco-2 cells. J. Funct. Foods, 39: 84-90. DOI: 10.1016/j.jff.2017.10.006

Palanisamy, S., M. Vinosha, M. Manikandakrishnan, R. Anjali and P. Rajasekar et al., 2018. Investigation of antioxidant and anticancer potential of fucoidan from Sargassum polycystum. Int. J. Biol. Macromol., 116: 151-161.

DOI: 10.1016/j.ijbiomac.2018.04.163
Pereira, J.A., I. Oliveira, A. Sousa, P. Valentao and P.B. Andrade et al., 2007. Walnut (Juglans regia L.) leaves: Phenolic compounds, antibacterial activity and antioxidant potential of different cultivars. Food Chem. Toxicol., 45: 2287-2295.

DOI: 10.1016/j.fct.2007.06.004

Ren, D., Y. Jiao, X. Yang, L. Yuan and J. Guo et al., 2015. Antioxidant and antitumor effects of polysaccharides from the fungus Pleurotus abalonus. Chem. Biol. Interact., 237: 166-174.

DOI: 10.1016/j.cbi.2015.06.017

Shi, X.D., S.P. Nie, J.Y. Yin, Z.Q. Que and L.J. Zhang et al., 2017. Polysaccharide from leaf skin of Aloe barbadensis Miller: Part I. Extraction, fractionation, physicochemical properties and structural characterization. Food Hydrocoll., 73: 176-183. DOI: 10.1016/j.foodhyd.2017.06.039

Suresh, V., N. Senthilkumar, R. Thangam, M. Rajkumar and C. Anbazhagan et al., 2013. Separation, purification and preliminary characterization of sulfated polysaccharides from Sargassum plagiophyllum and its in vitro anticancer and antioxidant activity. Process Biochem., 48: 364-373. DOI: 10.1016/j.procbio.2012.12.014

Tang, L., Y. Chen, Z. Jiang, S. Zhong and W. Chen et al., 2017. Purification, partial characterization and bioactivity of sulfated polysaccharides from Grateloupia livida. Int. J. Biol. Macromol., 94: 642-652. DOI: 10.1016/j.ijbiomac.2016.10.067

Tapia, M.I., J.R. Sánchez-Morgado, J. García-Parra, R. Ramírez and T. Hernández et al., 2013. Comparative study of the nutritional and bioactive compounds content of four walnut (Juglans regia L.) cultivars. J. Food Com. Analys., 31: 232-237. DOI: 10.1016/j.jfca.2013.06.004

Wang, C.Y., T.C. Wu, S.L. Hsieh, Y.H. Tsai and C.W. Yeh et al., 2015. Antioxidant activity and growth inhibition of human colon cancer cells by crude and purified fucoidan preparations extracted from Sargassum cristaefolium. J. Food Drug. Anal., 23: 766-777.

DOI: $10.1016 /$ j.jfda.2015.07.002

Wang, X., A. Gao, Y. Jiao, Y. Zhao and X. Yang, 2018. Antitumor effect and molecular mechanism of antioxidant polysaccharides from Salvia miltiorrhiza Bunge in human colorectal carcinoma LoVo cells. Int. J. Biol. Macromol., 108: 625-634. DOI: 10.1016/j.ijbiomac.2017.12.006

Wu, Y., Y. Li, C. Liu, E. Li and Z. Gao et al., 2016. Structural characterization of an acidic epimedium polysaccharide and its immune-enhancement activity. Carbohydr. Polym., 138: 134-142. DOI: 10.1016/j.carbpol.2015.11.014 
Xie, J.H., Z.J. Wang, M.Y. Shen, S.P. Nie and B. Gong et al., 2016. Sulfated modification, characterization and antioxidant activities of polysaccharide from Cyclocarya paliurus. Food Hydrocoll., 53: 7-15. DOI: 10.1016/j.foodhyd.2015.02.018

Yan, C., W. Sun, X. Wang, J. Long and X. Liu et al., 2016. Punicalagin attenuates palmitate-induced lipotoxicity in HepG2 cells by activating the Keap1Nrf2 antioxidant defense system. Mol. Nutr. Food Res., 60: 1139-1149. DOI: 10.1002/mnfr.201500490

Yang, S., Y. Li, D. Jia, K. Yao and W. Liu, 2017. The synergy of Box-Behnken designs on the optimization of polysaccharide extraction from mulberry leaves. Ind. Crop. Prod., 99: 70-78.

DOI: 10.1016/j.indcrop.2017.01.024

Yin, C., X. Fan, Z. Fan, D. Shi and H. Gao, 2018. Optimization of enzymes-microwave-ultrasound assisted extraction of Lentinus edodes polysaccharides and determination of its antioxidant activity. Int. J. Biol. Macromol., 111: 446-454. DOI: 10.1016/j.ijbiomac.2018.01.007

Yu, Y., M. Shen, Q. Song and J. Xie, 2018. Biological activities and pharmaceutical applications of polysaccharide from natural resources: A review. Carbohydr. Polym., 183: 91-101.

DOI: 10.1016/j.carbpol.2017.12.009
Yuan, J.F., Z.Q. Zhang, Z.C. Fan and J.X. Yang, 2008. Antioxidant effects and cytotoxicity of three purified polysaccharides from Ligusticum chuanxiong Hort. Carbohydr. Polym., 74: 822-827.

DOI: 10.1016/j.carbpol.2008.04.040

Zhou, J., G. Xu, J. Yan, K. Li and Z. Bai et al., 2015. Rehmannia glutinosa (Gaertn.) DC. polysaccharide ameliorates hyperglycemia, hyperlipemia and vascular inflammation in streptozotocin-induced diabetic mice. J. Ethnopharmacol., 164: 229-238. DOI: $10.1016 /$ j.jep.2015.02.026

Zhou, L., Z. Liu, Z. Wang, S. Yu and T. Long et al., 2017. Astragalus polysaccharides exerts immunomodulatory effects via TLR4-mediated MyD88-dependent signaling pathway in vitro and in vivo. Scientific Rep., 7: 44822-44822. DOI: $10.1038 /$ srep44822

Zhu, Y., Q. Li, G. Mao, Y. Zou and W. Feng et al., 2014. Optimization of enzyme-assisted extraction and characterization of polysaccharides from Hericium erinaceus. Carbohydr. Polym., 101: 606-613. DOI: 10.1016/j.carbpol.2013.09.099 